\title{
CLASSIFICATION OF RESIDENTIAL BUILDINGS IN THE OLD CITY OF HEBRON
}

\author{
GHASSAN J. DWEIK \& WAEL S. SHAHEEN \\ Department of Civil and Architectural Engineering, College of Engineering, \\ Palestine Polytechnic University, Hebron, Palestine
}

\begin{abstract}
The architectural style of buildings in Hebron's Old City - Hebron, a Palestinian city - is the same as that of most Islamic world cities and takes the form of houses with internal backyards. This is a result of the conditions particular to Islamic society in which residential areas have narrow streets, covered markets, mosques surrounded by a safe zone, and stone-paved courtyards. Visitors to Hebron discover pleasing architectural vistas and associated aesthetics. They may be amazed at how Muslim architects have built constructions that match the environmental and psychological conditions to enable integration between dwellings and humans in a secure form that does not violate the environment. The principles of architecture were based on the welfare of the residents for whom the houses were built. Areas of privacy were made for the collective activities of extended families, with greater privacy for smaller families. Efforts were made to ensure comfort in the house. Thus, houses were constructed while taking the local environment into consideration to ensure the comfort of the residents. The fact that several houses shared the same external walls helped to make people living in Hebron feel safe. The buildings formed a type of wall around the Old City in which each house shaded the other and also provided shade to passers-by. These factors were all taken into account by the Muslim architect, who followed the rules of Islam on the principles of construction.

Keywords: conservation, Hebron old city - Palestine, residential buildings, privacy.
\end{abstract}

\section{INTRODUCTION}

Most of the new Palestinian architects did not understand and appreciate the suitability of the old traditional houses, especially those who had studied in the western countries. They returned with the idea of the (closed house), which was developed in the west. But this new type of house plan has not answered the principle demands of Hebron's society, such as religious and considerations, nor has it satisfactorily met climatic conditions or proved compatible with local materials. So, the importance of the old buildings, besides their sturdiness and their resistance is that the majority of them have been available for living in until now.

They also illustrate the way in which, in the past the Palestinian people solved the basic challenges of religious and social demands, climatic and economic factors, which the new architecture up to date has ignored. For example, many modern houses are detached, which the maximum area exposed to direct sunlight, and with large climatically unprotected windows.

Traditional houses are mainly found in the old city of Hebron and in the old quarters, such as Haret Al Sawakneh and Haret Al Aqqabeh. They are mainly grouped around a focal point such as a community mosque, a market place, or both [1].

The traditional houses in Hebron can be classified under two main categories: the residential type and the residential-commercial type.

The residential type is usually located within the family compound, the Hamuleh. Each Hamuleh used to build its own houses in a neighborhood, known in Hebron society by the term "Harat", for example Haret Al Sawakneh, Haret Al Ja'abreh and Haret Al Aqqabeh. 
Within the Hamuleh compound, there are different plans or small and large houses; and each responding to its inhabitant's needs (Fig. 1).

The residential-commercial type includes those houses which have a commercial component. These houses are mainly found on major access roads leading to the main shopping area, but they are can also be integrated with the shopping area, forming Al Suq (a market).

The majority of traditional houses have their own utility services, including well-water and sanitary pits, although some of them have recently been connected to the municipal services network (Fig. 2).

The influence of Islam on the design of housing is as significant as the particular demands which other elements of the organization of Palestinian society make on the designer and builder of houses. The Muslim family requires in the form of building it lives in a combination of maximum privacy for the house hold and provision for the close relationships which tend to exist between families and their neighbors. Therefore, the house must be facilities for hospitality and social contact, but allow privacy to be retained. Further, the demands of religion, such as the inclusion of elements of paradise (e.g. house plants and water) and the orientation of building towards Mecca must be taken into account. Most houses built in traditional style in the West Bank have their form dictated by factors related Palestinian culture and way of life. This is particularly, so, in the case of houses in the old city of Hebron where aspects such as the design of entrances and windows exemplify the social and religious requirements of the inhabitants [2].

\section{TRADITIONAL RESIDENTIAL HOUSES IN HEBRON}

Some of the residential houses in Hebron's Old City date back to the late Mamluk period, at least those on the ground floor, and other architecture elsewhere dates from the Ottoman period (1517-1917).

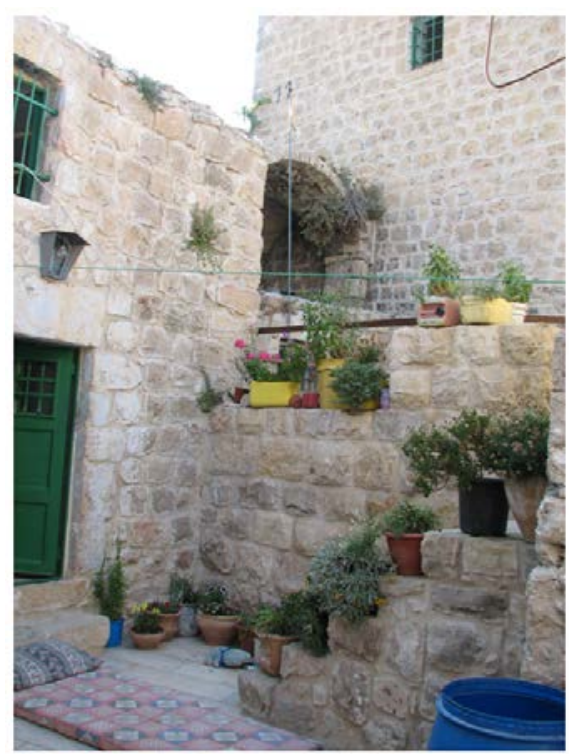

Figure 1: Residential type.

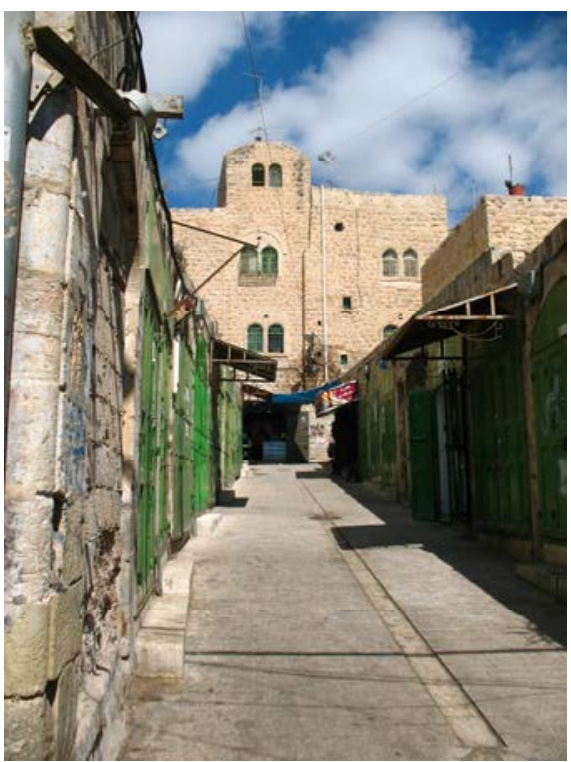

Figure 2: Residential-commercial type. 
During the Mamluk period, Al-Hanbali described the houses of Jerusalem and Hebron as: "Buildings in Bait al-Maqdis are clinch and professional; all of them have been constructed with carved white stone, and the ceiling is a cross-vault with no clay or wood. There are no better buildings in cities in Palestine than those in Bait al-Maqdis or the city of al-Khalil (PBUH). The buildings of Jerusalem are well-mastered, and nothing came close to them except those in Nablus." Al-Balwi Abu el-Baqa'a Khalid ibn Issa (died 780 AH/1378 AD) described the houses of Hebron and may be the only one of the Muslim or foreign explorers who visited the city to mention that the houses were white in color with green edging around them. He made this remark almost one hundred and twenty years before AlHanbali [3].

Houses from the Mamluk period were cared for lovingly by residents and owners as a source of comfort and shelter. The mountainous nature of the area was significant in determining the building material used: an extremely strong limestone that gave the city its special character. The houses of Hebron have unique domes that result in an attractive skyline visually. They also have wide backyards where wells are dug to store rainwater throughout the year. These houses are mostly two or three floors; the entrances to the backyards are low and no big doors were located onto the streets, except for a few houses. The houses are usually dark and in the shape of foyer that ends with a wide yard called the patio or the courtyard, Inside the house, there are residential units and a large room called the hall (for guests) that overlooks the patio or courtyard.

Houses built in the late Ottoman period in particular were close to each other, which led to vertical rather than horizontal expansion. Houses formed the city wall and have three floors (basement, central floor and sometimes an attic). This indicates the abundance of construction material (stone, lime, clay) and the extended families that led to an expanding population.

The residents of Hebron are generally of average stature and able-bodied. They work in agriculture, raising different types of livestock, mastering handicrafts (glass, copper, pottery, and knitting), labor in quarries and trade as a profession. Trade flourished in the days when pilgrim convoys used to pass through Hebron. The residents of Hebron eat the products of their own hands and drink water from rainwater-collecting wells. They wear simple loose Islamic clothing suitable for their daily activities (cultivation, industry, worship). Women in Hebron wear cloaks, cover their hair and cover their faces with a niqab. Hebron residents marry at a young age and it is common to find extended families that include a grandfather, father, sons and grandchildren. Hebron is well-known for polygamy. The residents of Hebron are famous for storytelling, poetry, mawal, zajal, dance and folklore songs in weddings and other occasions. The residents of Hebron represent all the Arab Islamic qualities: faith in God, purity, patience, asceticism, ardency gallantry, and courage.

\section{ARCHITECTURAL PLAN}

The design of traditional houses in the old city of Hebron is the product of evolution, knowhow and experience practiced by the Arab Muslim architecture in their search for comfort and to satisfy their needs in accordance with the climatic conditions and the prevailing environment, in addition to the satisfaction of the psychological and intellectual needs stemming from the comprehensive concept of life in Islam. Based on the dominant style in the old city of Hebron, which is adopted in constructing most houses of Palestinian rural and urban areas and continued to evolve with the development of the family concept, we could say that the horizontal projection of the whole houses and traditional residences in Hebron as part of this study narrates the story of the family inhabited it and the evolution 
that took place over the years. Any visitor to any Khalili house realizes that the house had developed through several stages. The evidence will be the diversity of stones used in constructing it. Such diversity demonstrates the difference in periods of time during which the house was built. The horizontal projection of traditional house suggests that house was initially constructed as a one or more bedroom house. By time, there was a need for a greater number of rooms in order to accommodate the increase in the number of family members; i.e. the family shifted from the nuclear to the extended family. The basic element helped in this matter is the presence of the inner courtyard where stairs could be constructed to have access to the second floor. Hence, it was possible to build more rooms as needed.

As it can be seen in the plan of Alja'beh residence, which is an evidence of the evolution of Khalili old residences which significantly holds the evidences of the eras that had gone through it. The ground floor consists of a linear courtyard surrounded by spaces of the ground floor. We could move from this yard into the other open or covered arenas giving more privacy and deemed to be semi-private spaces. Then, we gradually progress in privacy issue to reach the private rooms (bedrooms). Within the same courtyard there are stairs in different positions sending you to the upper floors of the house. The difference in patterns and styles of construction in the upper floors indicates that the house was built in more than a period of time. Such a difference in the style of floors shows the phases of constructing the house and the civilizations that did leave their marks on it.

We note in the projection of Al Dweik residence that the house consists of a central courtyard surrounded by rooms. Through this yard, you can move up to the upper floors which is again a replication of the idea of the yard surrounded rooms. Also, it shows the various eras that this house had gone through. We could note that the yard is shrinking in terms of size due to the construction of more rooms when required as the yard was partially roofed to convert this part to a room. The existence of stairs inside the courtyard indicates that the expansion process was vertically rather than horizontally due to the fact that the house was limited by the walls of other houses which represent a protection element among these houses. Moreover, we need not to forget the values of Islam and the rights of the neighbor, including showing respect of the road sanctity, such as adding overhangs and the like.

The housing design in the old city of Hebron was not a complicated issue as per the construction standards of those days since the construction process was primarily based on customs and traditions inherited from father to son and generation after generation. This helped to have stability in values that are reflected in these steadfast buildings. In view of the fact that the architecture had to reflect these values on the house to achieve the desired objectives, these values were applied in a very simple way and easy to be understood. Yet, differences in projections of houses is often can be referred to the size of spaces and the area of the courtyard and entrance in some cases; however, the similarity among these projections lies in the main idea, i.e. the centralized courtyard surrounded by all rooms, all openings are overlooking the yard and stairs are used to move up to the upper floors. This pattern is replicated in all old houses of Hebron in a simple manner [4].

\section{ELEMENTS AND CHARCTERISTICS OF KHALILI RESIDENCE}

During the period and post period of Islam, residential architecture in Hebron is characterized by its genuine shapes corresponding to life conditions and requirements. These shapes are also stemmed from ideas derived from the Holy Qur'an and Sunnah of His Messenger which is deemed to be the mouthpiece of its environment and conditions. Indeed, they are not an imitation, fake or claim. Researchers of the traditional architecture in Hebron will feel the struggle of architects (skilled builders) to achieve development and 
progress. They will observe their successive experiences and the results of their sense and increasing understanding of the values of building materials. They will acknowledge their ingenuity and remarkable capacities to adapt with the different condition of regions.

\subsection{Entrance}

The entrance of the Khalili house is the first space that can be seen from the semi-public space (usually overlooks the deadlock road, alley or yard as it called in the local dialect). This space is usually located in the corner of the house. It is often the only part visible from the main entrance. It is characterized by solid walls or it may have few small windows in their lower parts and larger and bigger in upper floors. The entrance in Khalili house to a great extent is a key element. It reflects the importance of the house and symbolic values whose roots are derived from the Palestinian Arab Islamic culture, such as: benevolence, generosity and security (Al Dwaib 2005). The entrance and is architecturally defined as the divider or physical partition which separates the outer space and the family internal space. Normally, it is higher than the street level by one or two stair steps. According to the Islamic law and provisions, the entrances of houses across the street should not opposite to each other to achieve privacy. Additionally, the direction of the entrance is preferably to be to the south and slightly skewed toward the east toward Mecca for religious and psychological reasons.

\subsection{Distributor (corridor, vestibule, entrance hall)}

They are several areas used in the region (locally) and means roofed space between two unroofed spaces. In this case, this represents the inner courtyard, corridor or outside the street. It is the second space in Khalili house. It plays a key role as a control space between the corridors or outside street and the interior courtyard. Furthermore, it is the safety filter of the house and the controlling faucet between the guests' space (semi-private) and family space (private). Then, its major function as a channel transferring you from public to semiprivate and to private spaces to provide the privacy required. The space of this distributor (corridor or vestibule) is designed in a way that obscures the courtyard from the eyes of the passers-by, or even foreign guests. It is often designed in a Latin letter shape, i.e. it forms with the entrance a 90 degree angle shape but dimensions are different from house to another. It got no doors and facing the courtyard, whereas the solid wall faces the main entrance.

\subsection{The hall}

This is a large spacious room designated specifically to receive guests. This room usually, is similar to the rest of the rooms. It is located around the courtyard (patio), but it is the closest room to the end of the vestibule or the entrance lounge. It has a bit high openings in the direction of the internal yard, in addition to a bay for ventilation.

\subsection{The inner courtyard}

This is the key element in the house. It is the element of action as well as horizontal and vertical communication between its parts, as well as making use of its climatic features due to the availability of walls or trees shades. The courtyard is the place that can be used for holding and carrying out various household activities and events, such as: wedding parties, 
a place for cooking or as a storage and preparation of supplies. The courtyard is exactly like the heart of the house and the most dynamic part, connects the family's living spaces and used by all members of the family and mainly by women and children to carry out and practice their daily daytime activities enjoying its privacy. The courtyard of Khalili house is open from the top and rooms' openings overlooking it since there are no openings overlooking roads and alleys. This main courtyard usually relates to other secondary courtyards in floors above the floor where the main courtyard is located. This means that the main internal courtyard and other secondary courtyards create external environment within or inside the house. It is usually in the shape of square or rectangle with different dimensions depending on the area of the house as in Naser-Eddin courtyard. Sometimes the yard is designed longitudinally as stated above in Al Ja'abeh courtyard.

\subsection{Al Oudah (room)}

This room has multiple functions in houses of Hebron city. Historically, the word Oudah in Hebron city means a house or residence. It is a Turkish word and has the meaning of a house or room, while in Hebron city this word colloquially means a multi-purpose room. Al Oudah (room) was used in the traditional Khalili house for several purposes, such as: sleeping, sitting and dining and as a kitchen in some cases; this was so practical in Khalili house for extended and medium families. Each Oudah used to accommodate a whole nucleus family and has moving and simple furniture that can be easily rearranged between night and day events. It used to have hidden wall cabinets and in many cases it has Matawi (singular is Matwa) to set up what is owned by the family of simple furniture (mattresses, blankets, pillows, etc.), in addition to foodstuff and some household items.

\subsection{Kitchen}

Cooking place in Khalili house is usually located in the floor at the level of the entrance in one corner of the yard, and close to the water tank or the well door. Normally, it has a single window overlooking the patio, or in other cases it can be overlooking the outer space but this depends on the kitchen location but the window should be a little bit high. In some other cases, there is no kitchen at all; the cooking place will be in one of the corners of the inner courtyard in summer, and in winter times Wagga' (fire place) is used in one of the rooms. Generally, the kitchen area is small relative to the area of the house.

\subsection{Bathroom (toilet)}

Traditional houses did not have bathtubs as there are near public bathtubs in the neighborhoods. There were no bathrooms in Khalili houses as in modern times. Bathrooms in Khalili house used to be a somewhat long space used as a water closet and known as (the rest room). The front space of the toilet is used for washing clothes, while bathing at home was usually done at threshold of $\mathrm{Al} \mathrm{Oudah,} \mathrm{or} \mathrm{in} \mathrm{the} \mathrm{room} \mathrm{whose} \mathrm{floor} \mathrm{level} \mathrm{is} \mathrm{usually}$ lower than the level of Al Oudah.

\subsection{The store}

The store is usually located in the ground floors. This part of the house is considered an essential space in Khalili house as it is used to fulfill the economic need for food storage. Storage at home was applied in different patterns, for example, under the bench in the 
bedroom (Al Oudah). Storage in the life of Khalili individuals is deemed to be extremely important as they store their land crops, including wheat, dried vegetables, jam, molasses, olive oil, olives, raisins and dried fig which all in all collected from their lands in summer season.

\subsection{The roof}

The roof of Khalili house serves several functions and economic and social activities. The economic activities include drying fruits and vegetables in the summer to be consumed in the winter season. Also, it is used for rainwater harvesting and directing water to the well. As for the social activities, they include social and night gatherings, and in some cases it is used to sleep on it. In order to achieve privacy for those who are on the roof and residents in the neighborhood, walls of roofs are of appropriate height. The wall usually has clay oriels that allow fresh breeze to pass through and prevent others from seeing those who are on the roof.

\section{TYPES OF RESIDENTIAL BULDINGS IN THE OLD CITY OF HEBRON}

This topic sheds the light on the progression of residential buildings of the city of Hebron during the past centuries. Such progression includes the structure pattern of this type of popular architecture which is almost a kind of spontaneous architecture whose forms are inconsistent, and it can be considered a reflection of the social status in that era.

The houses examined in this section were built at different times and are in the process to disappear. This is due to negligence, misuse, Israeli occupation attempts to replace them through closure processes of vandalism acts or the pressure exerted by modern construction investment in this central area of the historical city. Hence, the study of these houses is of great importance as it reflects the important link of the history of the Palestinian residential architecture. Moreover, it is through this study, as it is mentioned earlier, the reader may be able to link the context of the historical development of the Palestinian contemporary architecture.

To be able to fully examine these houses, we need to know the types of houses appeared before this period of time and influenced the evolution of architecture of that era. Therefore, we designated a special appendix on houses in the Levant area since the early periods of endemism there.

\subsection{Classification of residential buildings}

Based on our records of the reality of residential buildings and the available references, we believe that some of the residential buildings in the old town of Hebron are dated back to the late period of Mamluk era. To be more accurate, some ground floors of those buildings or even parts of the buildings are dated back to this period. The rest parts of those buildings and other buildings are dated back to the period of Ottoman rule of Palestine (1516-1917).

\subsubsection{The classification of residential buildings as per occupants}

\section{Al Hoosh (yard) (collective houses)}

Al Hoosh in the language means the yard and it is used here in the sense of collective houses or units of houses overlooking the common yard. There are two examples of this type that will be tackled and explained in the subsequent chapters. These yards were inhabited by multiple families but from the same tribe. The families might be extended ones as the families used to inhabit Al Nasser Al Dein in Al Aqabah quarter or of simpler pattern as the families inhabited Al Ja'bah yard (Fig. 3). 

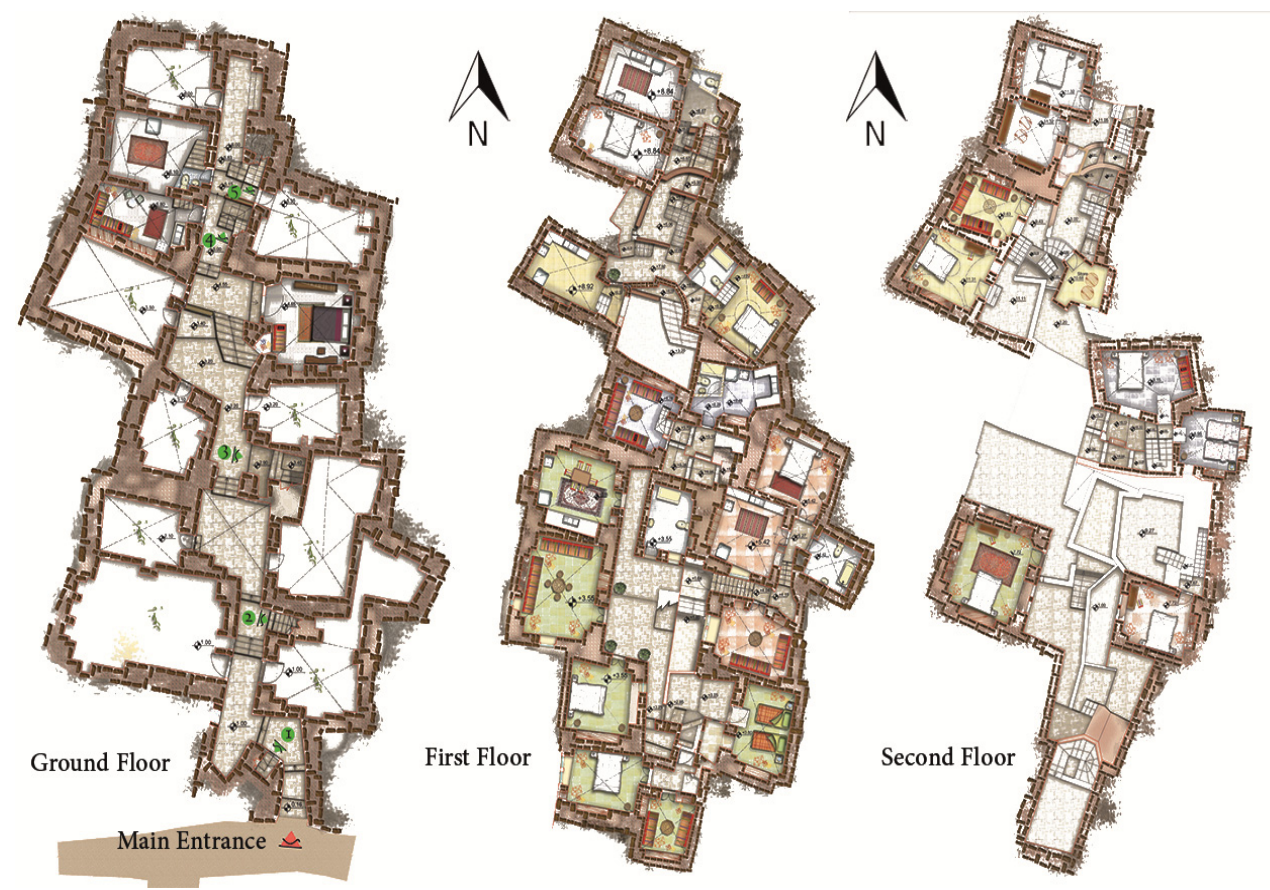

Figure 3: Collective houses overlooking the common yard.

\section{Single family house (includes relatives)}

This type of house was constructed for one family that might be extended family and it includes some relatives. They are often fully independent houses like the house of Al Dweik (Kurds quarter), houses directly above shops, such as the house of Shaheen, houses above the archways and streets such as the house of Salhab or houses within a joined fabric from all directions except the public street, such as Palestine Hotel.

\section{A house with a private yard}

Such types of houses are numerous in the old city of Hebron. The yards are of different shapes and the best examples of these buildings are Al Heriz and Al Sidr buildings.

\section{Single family house (without relatives)}

Such type of houses was built for one extended family and here no relatives inhabited with the family. In such family houses the ground floor or the basement, if any, was designated for services, such as a barn for animals, other places as stores and in some cases workshops to serve the industry of the owner's business. As for the first floor, it was dedicated for day activities, such as a place to cook and other activities like receiving guests. The higher floors are often assigned as bedrooms. These types of buildings are usually located on the outskirts of the old city; an example of this type of houses is houses of the Salhab Al Natsheh (Fig. 4). 

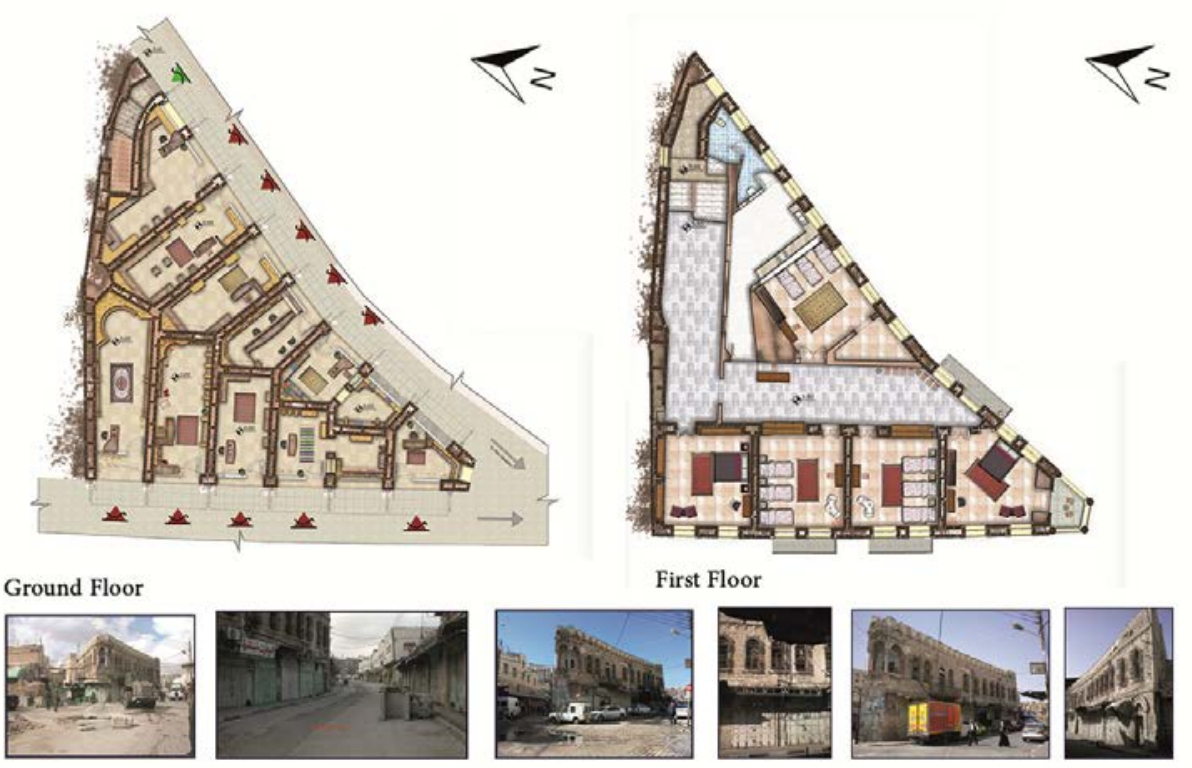

Figure 4: Extended family house.

\subsubsection{Classification as per shape and structure}

Residential buildings have been classified as per their shape and structure into five patterns. They are:

\section{Hoosh (Yard) building within an urban fabric}

This style of buildings emerged as a result of the nature of the prevailing family structure. The family system relied on big extended family, which consists of parents and children and their families. This combination had an observable impact on the design of the housing unit in particular, where Hoosh (yard) system appeared and deemed to be the basic unit of the urban structure. Families of the same origin got together in specific quarters. This was reflected on the overall composition of the city where such composition appeared as clusters of knit fabric resulting from the random contact and overlap of these yards. Those buildings were features by their simple design and spontaneity of architectural configuration paying no attention for decoration and the construction of facades. Security issues, infighting besides the economic factors facilitated the emergence of the pattern of buildings.

An example of this pattern is Al Ja'abeh yard, Naser Al Dein yard, Al Imam house and Al-Shaheen house (Fig. 5).

\section{Hoosh (Yard) building within a nucleus of an urban fabric}

This style was unique in its incomplete urban fabric. Therefore, we see that there is still a part of the land is not utilized to build a house in it. Also, this pattern relied on big extended family system which consists of parents, children and their families.

Examples of this type of buildings are Al Natsheh yard where we noticed that part of the land was left and was not included in the urban fabric. That was a clear conclusion when we analyzed the internal courtyard (Fig. 6). 


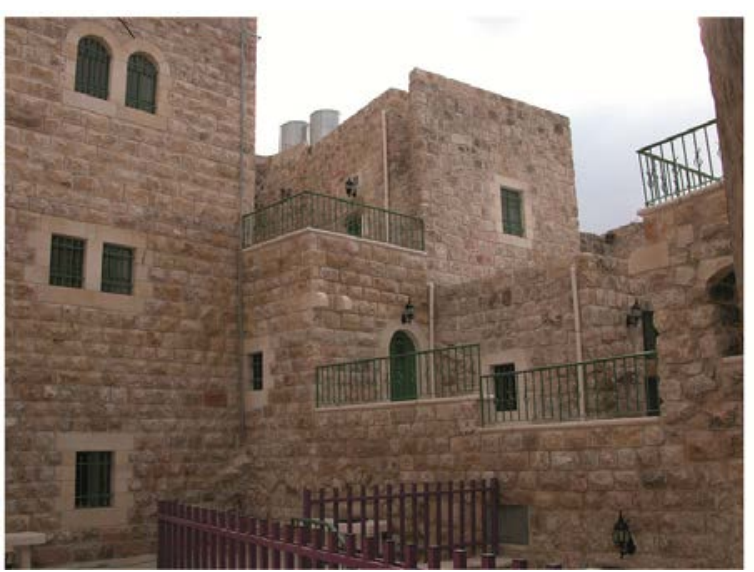

Figure 5: Building within an urban fabric.

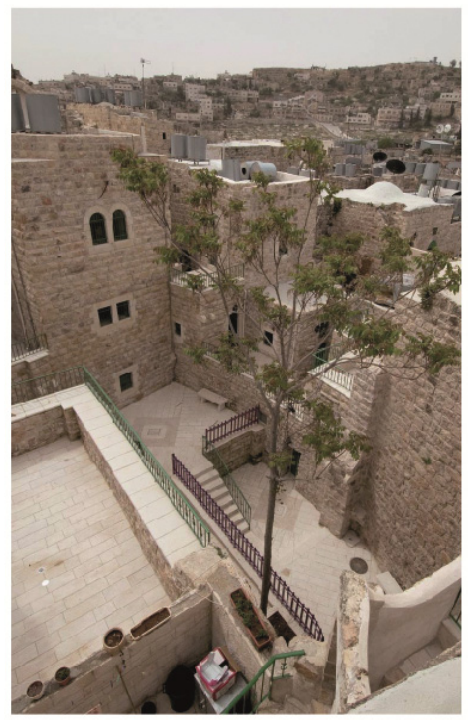

Figure 6: Building within a nucleus of an urban fabric.

\section{A building within a group of buildings (bar)}

This pattern is distinguished by its shape as a horizontal bar within a group of buildings. This means that the building is linked to other buildings from one or both sides. This pattern has numerous functions and usages, as some of these buildings are residentialindustrial and some are residential- commercial.

This pattern becomes evident in Palestine Hotel which is a residential- commercial building overlooking its commercial shops on Old and New Shalala Streets.

\section{A single outstanding building (palace)}

This pattern of buildings appeared as a result of the state of security and stability, in addition to the high standard of living attributable to the agriculture and industry boom. The rich began to build their houses outside the old urban fabric range paying more attention to the residential buildings, either through the internal distribution (horizontal projection) or through the facades.

This pattern was clear in particular in Al Dweik residential building which is featured by its facades and decorations (Fig. 7).

\section{A single simple building}

This pattern is featured by its simple shape and internal distribution. The horizontal projection is often comes in a rectangle or square shape. The internal distribution depends on the existence of an inner roofed courtyard (liwan) where spaces are distributed symmetrically on its both sides. In most cases, spaces are distributed in one floor and sometimes in two floors. As for facades, they are very simple with no decorations or other works.

An example of this pattern is Al Sidr building in Kurds quarter. 


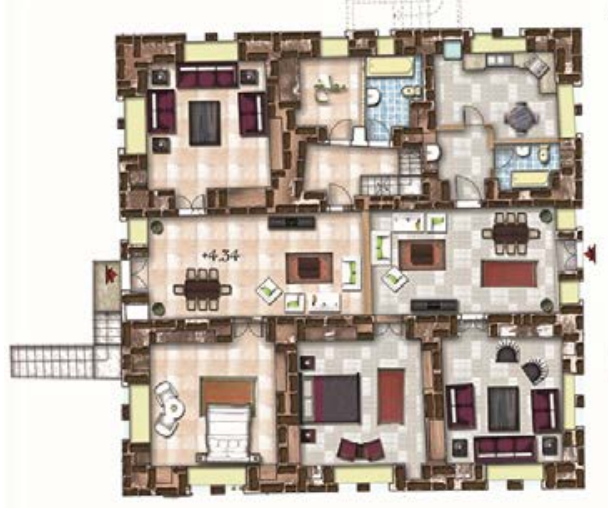

First Floor

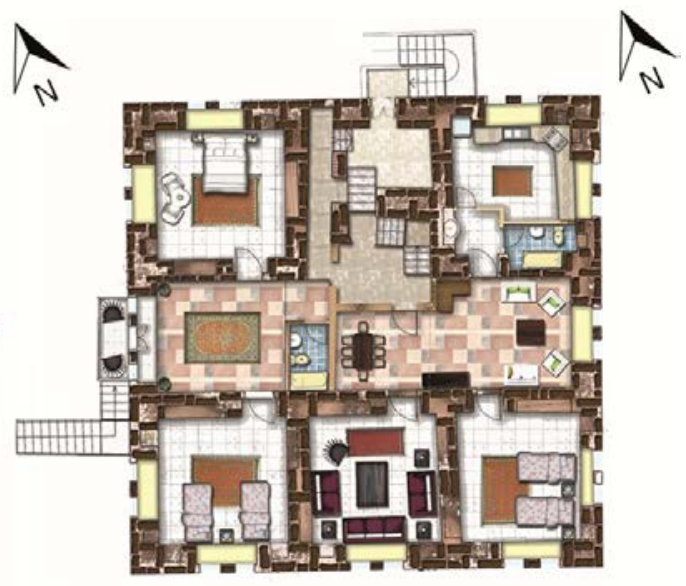

Second Floor

Figure 7: A single outstanding building (palace).

\subsubsection{Classified by usage}

Buildings are classified based on their usages and functions into two categories:

\section{Residential building}

This type is used only as a residence only. This is the case with most of the residential buildings in the old city.

\section{Residential-commercial building}

The ground floors of this type of buildings consist of shops overlooking the various types of markets, while the upper floors are used as houses. This pattern is evident in Palestine Hotel.

\section{CONCLUSION}

Since the late $17^{\text {th }}$ century evolution and change in the site layout, plan typology and architectural form of the Palestinian traditional dwellings has been witnessed. The result of this change was a significant shift in traditional trends from the pre- $19^{\text {th }}$ century organic compact texture, consisting of attached irregular extended family houses, to the early- $20^{\text {th }}$ century individual central hall garden houses. The new types of housing overlapped with a social shift in the family structure moving from extended to nucleus. In Palestine and particularly in Hebron, this new type of housing would not be adopted easily if Palestinians were not ready for changing their traditional social hierarchy of extended families and their larger clan relationships. The central hall house adoption was complementary to this social shift, and therefore it was easily accepted in the Palestinian urban centers. Furthermore, the central hall house was part of a fashion, which appeared in Palestine as well as in surrounding Arabic native and non-Arabic native habitation centers of the Ottoman Empire.

\section{RECOMMENDATIONS FOR FUTURE RESEARCH}

More research on traditional Palestinian architecture in specific areas and their surrounding geographical regions needs to be out. As much houses and habitation centers are investigated, more valuable and wide-reaching research findings can be found. This thesis 
provides a reference for researchers who are interested at establishing comparisons among the traditional residential architecture of the Middle East and other parts of the world.

Regarding Hebron old city research needs to be fulfilled on the urban from the traditional part of the town. The traditional neighborhoods should be documented properly, with special consideration given to the three-dimensional settings of the buildings and the urban and the urban fabric. The traditional part of the town has a very rich architectural and urban emphasis, from which the new generations of architects and master builders can learn a great deal.

\section{REFERENCES}

[1] Ghassan, J.D., Revitalization of the old city of Hebron, PhD research, Bucharest, Romania, 1998.

[2] Hebron Rehabilitation Committee, Old Hebron, The Charm of a Historical City and Architecture, HRC: Hebron, Palestine, 2009.

[3] Abdelhafez, A.S., Urban development of Hebron city, PhD thesis, Kiev, Ukraine, 2002.

[4] Hebron Rehabilitation Committee, RAWIQ, Swedish International Development Cooperation Agency (SIDA), Survey of the traditional town neighbourhoods and buildings. HRC: Hebron, Palestine, 2001. 